\title{
Platelet Transfusion in the Neonatal Intensive Care Unit: Benefits, Risks, Alternatives
}

\author{
Robert D. Christensen \\ Women and Newborns Program, Intermountain Healthcare, and Primary Children's Medical Center, Salt Lake City, \\ Utah, and Division of Neonatology, McKay-Dee Hospital Center, Ogden, Utah, USA
}

\section{Key Words}

Thrombocytopenia $\cdot$ Reference range $\cdot$ Transfusion $\cdot$

Platelets $\cdot$ Neonatal intensive care unit $\cdot$ Mean platelet

volume $\cdot$ Practice guidelines

\begin{abstract}
Platelet transfusions were introduced into clinical medicine about 60 years ago when they were shown to reduce the mortality rate of patients with leukemia who were bleeding secondary to hyporegenerative thrombocytopenia. In modern neonatology units, platelet transfusions are integral and indeed lifesaving for some neonates. However, the great majority of platelet transfusions currently administered in neonatal intensive care units (NICUs) are not given in the original paradigm to treat thrombocytopenic hemorrhage, but instead are administered prophylactically with the hope that they will reduce the risk of spontaneous bleeding. Weighing the risks and benefits of platelet transfusion, although imprecise, should be attempted each time a platelet transfusion is ordered. Adopting guidelines specific for platelet transfusion will improve consistency of care and will also generally reduce transfusion usage, thereby reducing costs and conserving valuable blood bank resources. Initiating specific programs to improve compliance with transfusion guidelines can further improve NICU transfusion practice.
\end{abstract}

Copyright $\odot 2011$ S. Karger AG, Basel (c) 2011 S. Karger AG, Basel

$1661-7800 / 11 / 1003-0311 \$ 38.00 / 0$

Fax +41613061234 E-Mail karger@karger.ch www.karger.com
Accessible online at:

www.karger.com/neo

\section{The Reference Range Concept in Neonatal Hematology}

The term 'thrombocytopenia' indicates a low concentration of platelets in the blood. For decades the definition of thrombocytopenia, among patients of all ages, has been a platelet count $<150,000 / \mu l[1,2]$. However, a more accurate method to define any abnormal clinical laboratory test is to identify values that fall outside the appropriate 'reference range'. Reference ranges are particularly applicable to neonatology because 'normal ranges' for laboratory tests are not available for neonates. This is because blood is not drawn on healthy neonates for the purpose of establishing normal ranges, as is generally done with adults. Instead, 'reference ranges' are used, which consist of the 5 th to 95 th percentile values assembled from very large numbers of neonates with minimal pathology or with pathology not thought to be relevant to the laboratory parameter under study. Using this approach, it is clear that, among preterm infants, the long-held definition of thrombocytopenia (platelet count $<150,000 / \mu \mathrm{l}$ ) is overly simplistic, inaccurate, and sometimes quite misleading.
Dr. Robert D. Christensen

Intermountain Healthcare

4th Floor, 4401 Harrison Blvd.

Ogden, UT 84403 (USA)

Tel. +1 801387 4300,E-Mail rdchris4@ihc.com 
Fig. 1. The first recorded platelet counts (a) and MPV determinations (b) obtained in the first 3 days after birth are shown for neonates of 22-42 weeks' gestation. a Initial platelet counts. b Initial MPV measurements.
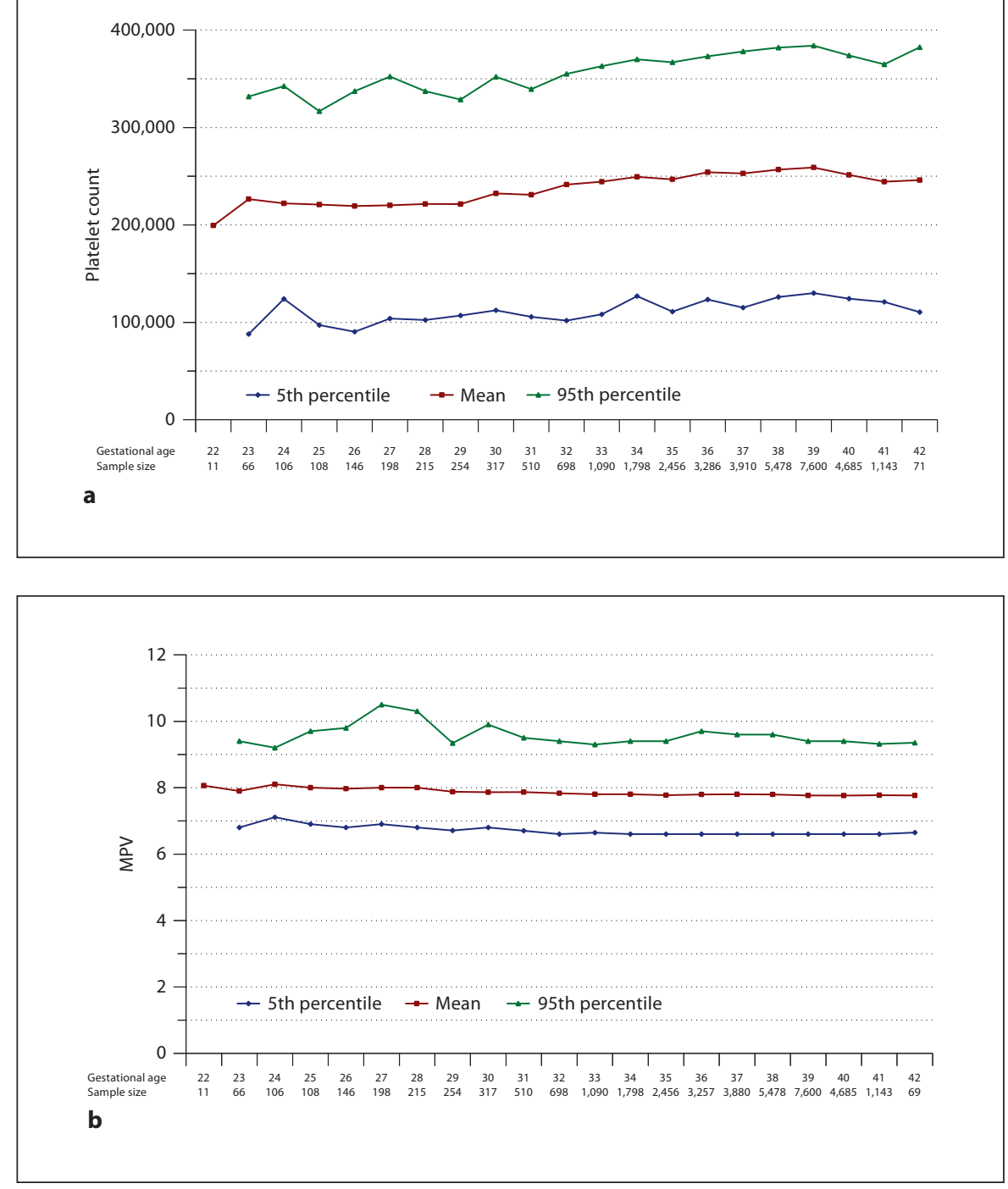

\section{Defining the Reference Ranges for Platelet Count and Mean Platelet Volume in Preterm and Term Neonates Using Large Multihospital Databases}

Reference ranges for blood concentrations of platelets in preterm and term infants on the day of birth are shown in figure 1a [3]. For neonates below 33 weeks' gestation, the 5th percentile value is approximately $100,000 / \mu 1$. Thus, platelet counts in the range of $100,000-150,000 / \mu l$, previously termed 'mild thrombocytopenia', should be recognized as within the reference range and therefore not abnormal. Although the reference ranges for platelet counts increase gradually from 23 to 40 weeks' gestation, the mean platelet volume (MPV) stays the same during this period (fig. 1b) [3].
Platelet counts are expected to gradually rise during the first 2 weeks following birth. As shown in figure 2a, counts at 14-21 days of age are generally $50 \%$ higher than they were at birth. This increase is likely the result of a physiological surge of thrombopoietin (Tpo) at birth [46]. Tpo is the primary physiological regulator of platelet production. Similarly, MPV increases over the first 14 days following birth (fig. 2b), likely indicative of accelerated platelet production. When the reference range concept is applied to preterm and term neonates, the definitions of thrombocytosis and thrombocytopenia are both seen to be highly dependent on postnatal age [3]. 
Fig. 2. The effect of advancing postnatal age on platelet counts (a) and MPV (b) during the first 90 days following birth. Percentile curves in a were manually smoothed and curves in $\mathbf{b}$ were mathematically smoothed. a Platelet counts during the first 90 days after birth. b MPV measurements during the first 90 days after birth.
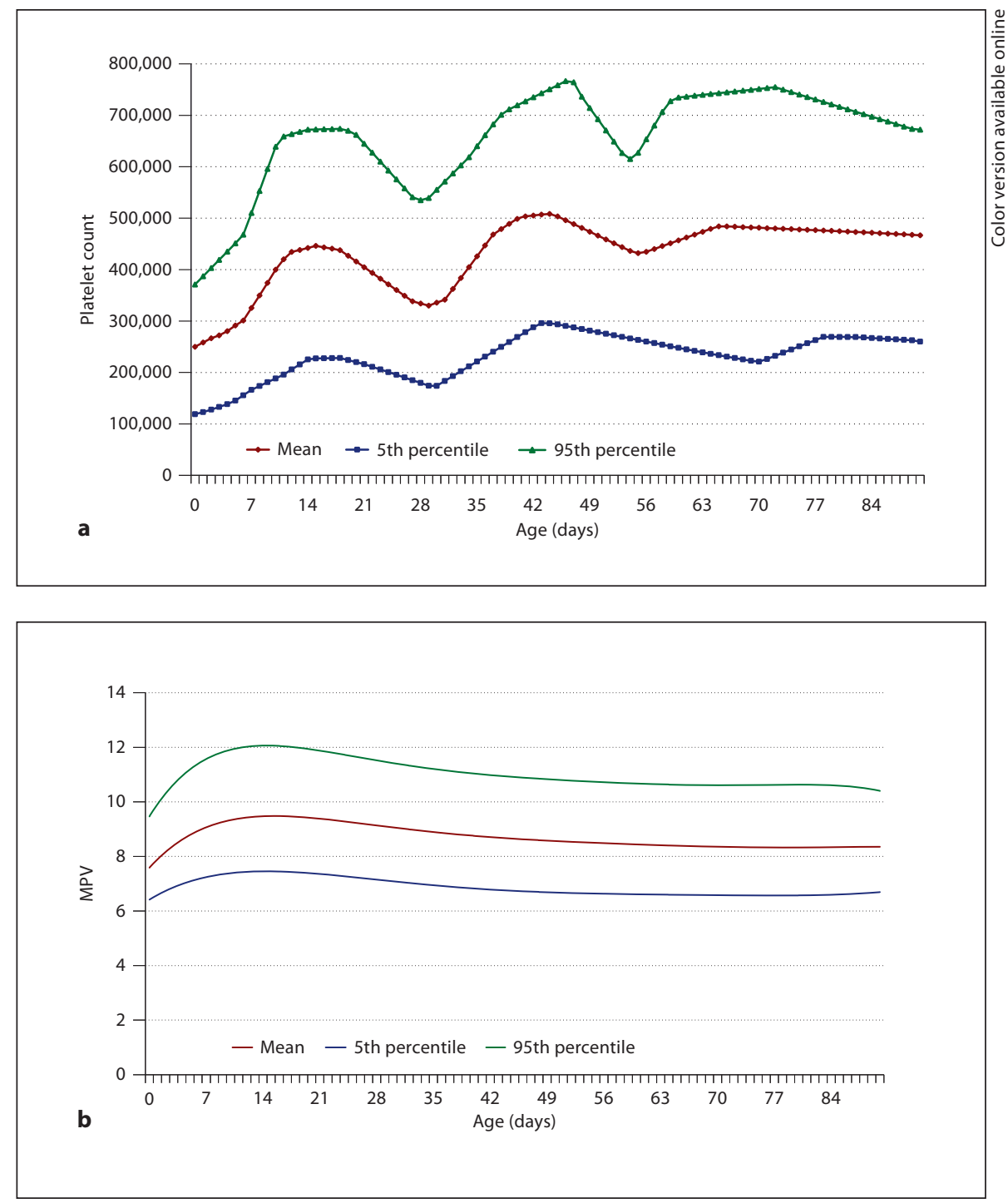

\section{Relationships between Maternal and Fetal Platelet Counts}

Discovering thrombocytopenia in a pregnant woman can be concerning to families and physicians, including the pediatricians and/or neonatologists planning to provide care for the neonate. The reference range for platelet counts during pregnancy changes by trimester (fig. 3a) [7]. Largely the result of dilution of mother's blood by her expanding plasma volume, her platelet counts gradually fall as pregnancy progresses; however, her MPV does not change (fig. 3b). The lower reference range for platelet count during the third trimester is about $115,000 / \mu \mathrm{l}$; thus maternal platelet counts in the range of 115,000 $150,000 / \mu l$, previously termed 'mild thrombocytopenia' are in fact within the reference range and, thus, should not be considered abnormal.

Pregnant women with a platelet count $<50,000 / \mu l$ most likely have hematopathology such as ITP or HELLP syndrome; however, a variety of causes have been identified and perhaps $20-25 \%$ of these women have no recognized etiology for their thrombocytopenia. If a woman's platelet count is $>75,000 / \mu l$ at delivery, it is unlikely that her neonate will have thrombocytopenia because in this population of patients there is no correlation between maternal and fetal platelet count [7]. However, if her platelet count is $<50,000 / \mu \mathrm{l}$ at delivery, the relative risk of severe thrombocytopenia in her neonate is increased by about 8 -fold. Based on this, we advise measuring the neonate's platelet count when the mother's count is found to be $<50,000 / \mu l$ [7]. 
Fig. 3. Platelet counts $(n=92,518)$ obtained on pregnant women $(\mathrm{n}=41,887)$ according to trimester: first $(\mathrm{n}=28,266)$, second $(\mathrm{n}=24,573)$, and third $(\mathrm{n}=39,679)$. a Blood concentrations of platelets $\left(\times 10^{9} / 1\right)$. b Mean platelet volume (fl).
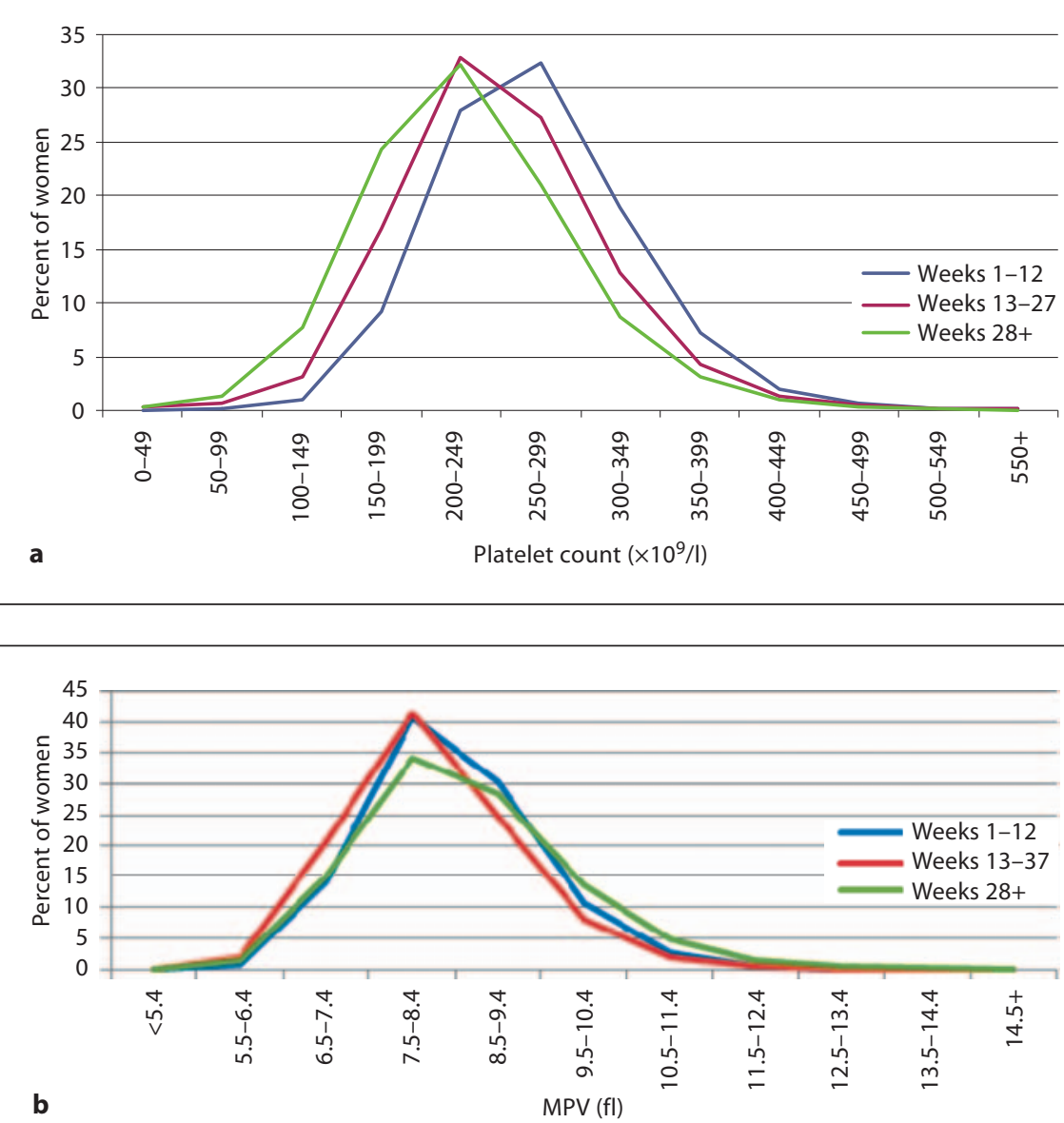

\section{Cause of Severe Thrombocytopenia in Neonatal Intensive Care Unit Patients}

Most cases of thrombocytopenia identified in the neonatal intensive care unit (NICU) are not severe. However, perhaps $25 \%$ of cases have a count that falls below $50,000 / \mu \mathrm{l}$, a threshold where the condition is generally termed 'severe neonatal thrombocytopenia' [8-10]. The majority of cases of severe neonatal thrombocytopenia are recognized at birth or shortly thereafter [8-10]. This is the case among extremely low birth weight (ELBW) neonates $(<1,000 \mathrm{~g})$ [8], and is also the case when all NICU patients are studied, regardless of gestational age [9]. Clearly, thrombocytopenia at anytime during the NICU stay is more common in the smallest patients, with a prevalence exceeding $80 \%$ of those weighing less than $600 \mathrm{~g}$ at birth [8], compared with about $1 \%$ of those weighing over 2,000 $\mathrm{g}$ at birth [8-10]. Biological differences have been observed between fetal, neonatal, and adult megakaryocytes, and these are likely involved in the marked susceptibility of ELBW neonates to develop thrombocytopenia [11].

While alloimmune neonatal thrombocytopenia is common among thrombocytopenic but otherwise healthy appearing term neonates [12-14], a wide variety of causes and associations are seen among ELBW neonates. Unfortunately, the largest etiologic category for thrombocytopenia among ELBW neonates is 'unknown or idiopathic' [8]. When an association or cause is known, the most common explanations are maternal hypertension, small for gestational age status, disseminated intravascular coagulation, bacterial or fungal infection, or necrotizing enterocolitis. 
Table 1. Pathological bleeding recorded in the medical records among 273 NICU patients with 326 episodes of severe thrombocytopenia

\begin{tabular}{lccllll}
\hline $\begin{array}{l}\text { Lowest platelet } \\
\text { count recorded }\end{array}$ & $\mathrm{n}$ & $\begin{array}{l}\text { Percent with cuta- } \\
\text { neous hemorrhage }\end{array}$ & $\begin{array}{l}\text { Percent with pulmo- } \\
\text { nary hemorrhage }\end{array}$ & $\begin{array}{l}\text { Percent with } \\
\text { GI hemorrhage }\end{array}$ & $\begin{array}{l}\text { Percent with } \\
\text { IVH (all grades) }\end{array}$ & $\begin{array}{l}\text { Percent with } \\
\text { grade 3 or 4 IVH }\end{array}$ \\
\hline$<20,000 / \mu l$ & 78 & $18^{1}$ & 8 & 5 & 29 & 17 \\
$20,000-30,000 / \mu l$ & 78 & 9 & 8 & 1 & 35 & 15 \\
$31,000-50,000 / \mu l$ & 117 & 9 & 6 & 2 & 32 & 19 \\
\hline
\end{tabular}

$\mathrm{GI}=$ Gastrointestinal.

${ }^{1}$ Cutaneous hemorrhage was more common if the lowest platelet count was $<20,000 / \mu l$ than if it was 20,000 to $50,000 / \mu l ; p<0.03$.

\section{Associations between Platelet Count and Clinical Hemorrhage}

Severe congenital thrombocytopenia from any etiology can predispose a fetus or neonate to a significant intraventricular (brain) hemorrhage (IVH) [1, 2, 12-14]. Such hemorrhages can occur in utero or during or after birth. In contrast, most preterm neonates who develop a severe IVH do not have thrombocytopenia before their $\mathrm{IVH}$, nor do they have a preexisting coagulopathy predating their IVH $[15,16]$. However, they can develop thrombocytopenia and coagulopathy after the IVH has occurred, due to tissue thromboplastin release within the brain hemorrhage [17]. Moreover, most preterm neonates who develop a small grade $1 \mathrm{IVH}$ that later extends to become a severe IVH do not have preexisting thrombocytopenia or coagulopathy [16]. Thus, while severe thrombocytopenia is a definite risk factor for IVH, the great majority of preterm infants who develop a severe IVH do not have preexisting thrombocytopenia as part of the pathogenesis of their hemorrhage. Administering platelet transfusions to neonates because they have mild or moderate thrombocytopenia does not prevent IVH [18-20].

In general, the correlation is poor between the neonate's platelet count and the odds of a clinical hemorrhage. As shown in table 1, this is the case for various types of neonatal hemorrhage. When severe thrombocytopenia (platelets $<50,000 / \mu \mathrm{l}$ ) is recognized in a neonate, underlying causes or associations are shown in table 2. Most cases of severe thrombocytopenia are associated with bacterial infection, small for gestational age or pregnancy-induced hypertension status, necrotizing enterocolitus, or disseminated intravascular coagulation [8-10].
Table 2. Explanations given in the medical records for severe thrombocytopenia

\begin{tabular}{ll}
\hline $\begin{array}{l}\text { Factors identified to explain the } \\
\text { thrombocytopenia }\end{array}$ & $\begin{array}{l}\text { Number of episodes (\% of total) } \\
\text { whereby this explanation was } \\
\text { given for the thrombocytopenia }\end{array}$ \\
\hline Bacterial infection & $91(25)$ \\
SGA or PIH & $78(22)$ \\
NEC & $52(14)$ \\
DIC & $48(13)$ \\
Unexplained or undiagnosed & $36(10)$ \\
Fungal infection & $27(8)$ \\
Alloimmune & $10(3)$ \\
Genetic & $7(2)$ \\
Thrombus & $6(2)$ \\
CMV & $5(1)$ \\
\hline
\end{tabular}

Values in parentheses represent percentages. 326 episodes of severe thrombocytopenia were detected among 273 NICU patients. 360 explanations were given for the 326 episodes because some episodes had two explanations given (e.g. bacterial sepsis plus DIC). SGA = Small for gestational age; $\mathrm{PIH}=$ pregnancy-induced hypertension; NEC $=$ necrotizing enterocolitis; DIC $=$ disseminated intravascular coagulation; $\mathrm{CMV}=$ cytomegalovirus.

\section{Guidelines for Administering Platelet Transfusions in the NICU}

Guidelines for platelet transfusions have been published [21-23]. Almost all platelet transfusions administered to neonates are 'prophylactic', meaning the patient is not actively bleeding but the transfusion is given with the intent of preventing bleeding [24]. Guidelines for prophylactic platelet transfusions are generally based on two considerations: (1) the condition of the neonate and (2) the platelet count. The reason for considering the condition of the neonate relates to the observation that stable 
Table 3. Guidelines for administering a prophylactic platelet transfusion to a newborn infant

\begin{tabular}{ll}
\hline Condition of the patient & Platelet mass $^{2}$ \\
\hline On ECMO or immediately pre- or post-op & $<800$ \\
Unstable $^{1}$ & $<400$ \\
Stable & $<160$ \\
\hline
\end{tabular}

A platelet transfusion would be ordered for a platelet mass below the level indicated, according to the condition of the patient. The product to be transfused is apheresis-produced, single-donor, irradiated, CMV 'safe', not packed. The volume of platelets should generally be $15-20 \mathrm{ml} / \mathrm{kg}$ body weight.

1 'Unstable' is not precisely defined but signifies a high risk for significant bleeding.

${ }^{2}$ Platelet mass is calculated by multiplying the platelet count (platelets/ $\mu \mathrm{l}$ ) by the MPV (fl). For example, a platelet count of $50,000 / \mu \mathrm{l}$ and an MPV of $9 \mathrm{fl}$ would equate to a platelet mass of 450 .

neonates seem to have a much lower risk of serious hemorrhage. For simplicity, the condition of the neonate can be grouped into one of three categories: (1) on ECMO or pre- or postoperative; (2) neither on ECMO nor pre- or postoperative, but 'unstable', or (3) 'stable'. Detailed definitions of these categories are generally lacking. For instance, the length of time pre- or postoperative has not been determined by data. Also precise definitions for 'unstable' and 'stable' are lacking, but these categories are intended to reflect a higher versus lower risk for a spontaneous significant hemorrhage.

Besides the clinical condition, the other usual consideration for platelet transfusion is the platelet count. Some guidelines advocate keeping the platelet count $>100,000 / \mu \mathrm{l}$ for neonates in the highest risk category (on ECMO or pre- or postoperative), $>50,000 / \mu l$ for those in the intermediate category (unstable) and $>20,000 / \mu 1$ for those in the lowest risk category (stable) [21-23].

The above approach is flawed in many ways; one of which is the lack of consideration for variation in platelet function. The capacity of platelets to form a hemostatically effective platelet plug [25] can be impaired in neonates receiving indomethacin [26], ibuprofen (to a lesser extent) [27], ampicillin [28, 29], inhaled nitric oxide [30], or therapeutic hypothermia [31]. Moreover, large platelets function better than small platelets to form an effective platelet plug [24]. This latter consideration can be incorporated into the platelet transfusion guidelines using the principle of 'platelet mass'. The platelet mass is a simple calculation, accomplished by multiplying the platelet count by the MPV. This calculation may reflect overall platelet function better than the platelet count alone. In a 2-NICU collaborative before versus after practice change study, we discovered that the use of platelet mass (rather than platelet count) in the transfusion decision reduced the number of prophylactic platelet transfusions given by about one third, with no increase in bleeding complications [24]. The reduction in transfusions came about because some neonates who qualified for a platelet transfusion on the basis of platelet count did not qualify on the basis of platelet mass since they had large platelets. Guidelines for prophylactic platelet transfusions based on platelet mass are provided in table 3.

\section{Compliance with Platelet Transfusion Guidelines}

Agreeing to abide by a set of practice guidelines for transfusion is a positive step toward better transfusion practice, but agreeing does not guarantee compliance in actual practice. Petäjä et al. [32] reported that only about $35 \%$ of platelet transfusions given were compliant with previously agreed upon guidelines. In the Intermountain Healthcare System, we audited all NICU transfusions given during the year 2006 and determined that about $65 \%$ of platelet transfusions were compliant with our guidelines, thus $35 \%$ were not [33]. In January 2009, we initiated a system-wide program aimed at increasing compliance with transfusion guidelines. This program included electronic order entry of transfusions, monthly reports to each NICU regarding compliance, and monthly reminders of the system-wide goal of improving to $90 \%$ compliance. The year began with transfusion compliance of about $60 \%$, but after a few months this increased to the goal level where it has remained ever since. Accompanying better compliance was a significant reduction in platelet transfusion usage, lower transfusion-related costs, and conservation of blood bank resources [34].

\section{Risks and Benefits of Platelet Transfusion in the NICU}

Platelet transfusions can be life-saving, but they also carry risks. Some such risks are at least partly defined, such as a risk of bacterial contamination of the donor platelets [35]. Other risks are poorly defined but still quantifiable. Figure 4 is typical of several reports showing a positive association between the number of platelet transfusions received and mortality rate [36-38]. This re- 


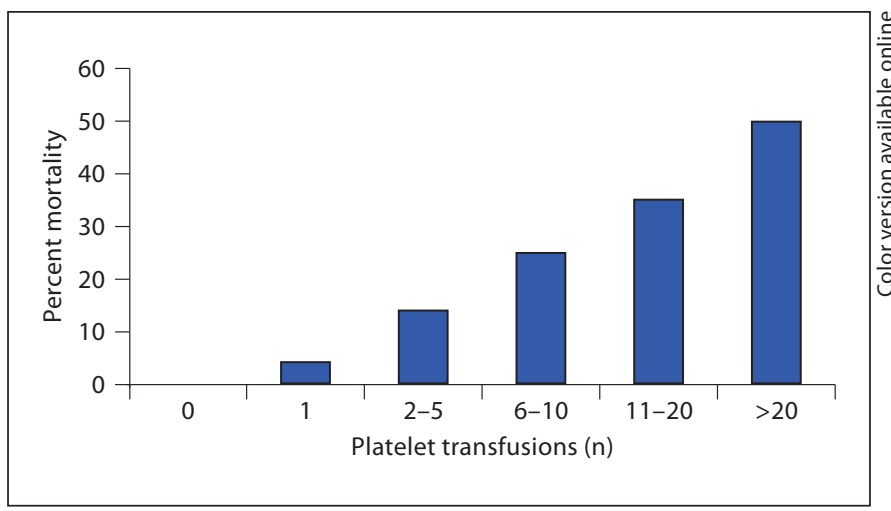

Fig. 4. Mortality rate of NICU patients with severe thrombocytopenia is displayed according to the number of platelet transfusions received.

lationship is multifactorial and complex, but analyses indicate a very high likelihood that the multiple transfusions themselves are involved in the elevated mortality rate [36].

It is not possible to precisely evaluate and contrast the risks versus benefits each time a platelet transfusion is considered in the NICU. Although imprecise, this process of attempting to weigh the risks and benefits is important before any platelet transfusion is ordered. Benefits are more likely in cases of thrombocytopenic hemorrhage than in cases where the platelets are given prophylactically. Unfortunately, some platelet transfusions are given in situations where the potential benefits are nil. Surveys indicate some clinicians give prophylactic platelet transfusions to stable neonates with platelet counts in the range of $100,000-150,000 / \mu 1$ [39]. Since the bleeding time is not prolonged in this platelet count range [40] and since these platelet counts are within the reference range, it is very unlikely that any benefit is provided by a platelet transfusion. Thus when well-appearing neonates receive prophylactic platelet transfusions because of a platelet count in the $100,000-150,000 / \mu l$ range, they are being subjected to risk unbalanced by any known benefit.

\section{Thrombopoietin Mimetics}

In 1994, Tpo was identified and the recombinant molecule became available for study [41]. Trials with Tpo and a pegylated form of Tpo were promising until some patients developed anti-Tpo antibodies, leading to aplastic anemia, which led to the cessation of development of this potential approach to treat thrombocytopenia. Subsequent studies focused on means of stimulating the Tpo receptor using molecules that have no homology with Tpo. Two such products have been approved by the US FDA: eltrombopag (GlaxoSmithKlein) and romiplostim (Amgen). Few neonates have been treated with either agent. No consistent approach or consensus for treatment has been developed for thrombocytopenic neonates, but caution has been issued [41, 42]. Tpo receptors have been identified on nonhematopoietic cells, including brain, and nonthrombopoietic actions during the neonatal period have not been defined.

\section{Disclosure Statement}

The author has no conflicts of interest regarding this work.

\section{References}

1 Roberts I, Stanworth S, Murray NA: Thrombocytopenia in the neonate. Blood Rev 2008; 22:173-186.

-2 Ferrer-Marin F, Liu ZJ, Gutti R, Sola-Visner M: Neonatal thrombocytopenia and megakaryocytopoiesis. Semin Hematol 2010;47: 281-288.

3 Wiedmeier SE, Henry E, Sola-Visner MC, Christensen RD: Platelet reference ranges for neonates, defined using data from over 47,000 patients in a multihospital healthcare system. J Perinatol 2009;29:130-136.

4 Murray NA, Watts TL, Roberts IA: Thrombopoietin in the fetus and neonate. Early Hum Dev 2000;59:1-12.
5 Sola MC, Calhoun DA, Hutson AD, Christensen RD: Plasma thrombopoietin concentrations in thrombocytopenic and nonthrombocytopenic patients in a neonatal intensive care unit. Br J Haematol 1999;104: 90-92.

-6 Kline A, Mackley A, Taylor SM, McKenzie SE, Paul DA: Thrombopoietin following transfusion of platelets in preterm neonates. Platelets 2008;19:428-431.
7 Jensen J, Wiedmeier SE, Henry E, Silver RM, Christensen RD: Linking maternal platelet counts with neonatal platelet counts and outcomes using the data repositories of a multihospital healthcare system. Am J Perinatol 2011, E-pub ahead of print.

8 Christensen RD, Henry E, Wiedmeier SE, Stoddard RA, Sola-Visner MC, Lambert DK, Kiehn TI, Ainsworth S: Thrombocytopenia among extremely low birth weight neonates: data from a multihospital healthcare system. J Perinatol 2006;26:348-353.

-9 Baer VL, Lambert DK, Henry E, Christensen RD: Severe thrombocytopenia in the NICU. Pediatrics 2009;124:e1095-e1100. 
10 Stanworth SJ, Clarke P, Watts T, Ballard S, Choo L, Morris T, Murphy MF, Roberts I, Platelets and Neonatal Transfusion Study Group: Prospective, observational study of outcomes in neonates with severe thrombocytopenia. Pediatrics 2009;124:e826-e834.

- 11 Hu A, Slayton WB, Rimsza LM, Bailey M, Sallmon H, Sola-Visner MC: Differences between newborn and adult mice in their response to immune thrombocytopenia. Neonatology 2010;98:100-108.

12 Bussel JB, Sola-Visner M: Current approaches to the evaluation and management of the fetus and neonate with immune thrombocytopenia. Semin Perinatol 2009;33:35-42.

13 Bussel JB, Primiani A: Fetal and neonatal alloimmune thrombocytopenia: progress and ongoing debates. Blood Rev 2008;22:33-52.

14 Murphy MF, Bussel JB: Advances in the management of alloimmune thrombocytopenia. Br J Haematol 2007; 136:366-378.

15 Baer VL, Lambert DK, Henry E, Snow GL, Butler A, Christensen RD: Among very-lowbirth-weight neonates is red blood cell transfusion an independent risk factor for subsequently developing a severe intraventricular hemorrhage? Transfusion 2011;51:11701178.

16 Baer VL, Lambert DK, Henry E, Snow GL, Christensen RD: Red blood cell transfusion of preterm neonates with a grade 1 intraventricular hemorrhage is associated with extension to a grade 3 or 4 hemorrhage. Transfusion 2011 DOI: 10.1111/j.1537-2995.2011. 03081.x.

17 Saxonhouse MA, Manco-Johnson MJ: The evaluation and management of neonatal coagulation disorders. Semin Perinatol 2009; 33:52-65.

18 Andrew M, Vegh P, Caco C, Kirpalani H, Jefferies A, Ohlsson A, Watts J, Saigal S, Milner $\mathrm{R}$, Wang E: A randomized, controlled trial of platelet transfusions in thrombocytopenic premature infants. J Pediatr 1993;123:285291.

19 von Lindern JS, van den Bruele T, Lopriore E, Walther FJ: Thrombocytopenia in neonates and the risk of intraventricular hemorrhage: a retrospective cohort study. BMC Pediatr 2011;11:16.

20 Dohner ML, Wiedmeier SE, Stoddard RA, Null D Jr, Lambert DK, Burnett J, Baer VL, Hunt JC, Henry E, Christensen RD: Very high users of platelet transfusions in the neonatal intensive care unit. Transfusion 2009; 49:869-872.

-21 Murray NA, Howarth LJ, McCloy MP, Letsky EA, Roberts IA: Platelet transfusion in the management of severe thrombocytopenia in neonatal intensive care unit patients. Transfus Med 2002;12:35-41.
22 Calhoun DA, Christensen RD, Edstrom CS, Juul SE, Ohls RK, Schibler KR, Sola MC, Sullivan SE: Consistent approaches to procedures and practices in neonatal hematology. Clin Perinatol 2000;27:733-753.

23 Gerday E, Baer VL, Lambert DK, Paul DA, Sola-Visner MC, Pysher TJ, Christensen RD: Testing platelet mass versus platelet count to guide platelet transfusions in the neonatal intensive care unit. Transfusion 2009;49: 2034-2039.

24 Estcourt LJ, Stanworth SJ, Murphy MF: Prophylactic platelet transfusions. Curr Opin Hematol 2010;17:411-417.

-25 Saxonhouse MA, Garner R, Mammel L, L Q, Muller KE, Greywoode J, Miller C, SolaVisner M: Closure times measured by the platelet function analyzer PFA-100 are longer in neonatal blood compared with cord blood samples. Neonatology 2010;97:242249.

26 Corazza MS, Davis RF, Merritt TA, Bejar R, Cvetnic W: Prolonged bleeding time in preterm infants receiving indomethacin for patent ductus arteriosus. J Pediatr 1984;105: 292-296.

27 Sheffield MJ, Schmutz N, Lambert DK, Henry E, Christensen RD: Ibuprofen lysine administration to neonates with a patent ductus arteriosus: effect on platelet plug formation assessed by in vivo and in vitro measurements. J Perinatol 2009;29:39-43.

28 Sheffield MJ, Lambert DK, Henry E, Christensen RD: Effect of ampicillin on the bleeding time of neonatal intensive care unit patients. J Perinatol 2010;30:527-530.

29 Sheffield MJ, Lambert DK, Baer VL, Henry E, Butler A, Snow GL, Christensen RD: Effect of ampicillin on bleeding time in very low birth-weight neonates during the first week after birth. J Perinatol 2011, E-pub ahead of print.

30 George TN, Johnson KJ, Bates JN, Segar JL: The effect of inhaled nitric oxide therapy on bleeding time and platelet aggregation in neonates. J Pediatr 1998;132:731-734.

31 Christensen RD, Sheffield MJ, Lambert DK, Baer VL: Effect of therapeutic hypothermia on platelet function in neonates with hypoxic-ischemic encephalopathy. Neonatology, in press.

32 Petäjä J, Andersson S, Syrjälä M: A simple automatized audit system for following and managing practices of platelet and plasma transfusions in a neonatal intensive care unit. Transfus Med 2004;14:281-288.
33 Baer VL, Lambert DK, Schmutz N, Henry E, Stoddard RA, Miner C, Wiedmeier SE, Burnett J, Eggert LD, Christensen RD: Adherence to NICU transfusion guidelines: data from a multihospital healthcare system. J Perinatol 2008;28:492-497.

34 Baer VL, Henry E, Lambert DK, Stoddard RA, Wiedmeier SE, Eggert LD, Ilstrup S, Christensen $\mathrm{RD}$ : Implementing a program to improve compliance with neonatal intensive care unit transfusion guidelines was accompanied by a reduction in transfusion rate: a pre-post analysis within a multihospital health care system. Transfusion 2011;51:264-269.

35 Rood IG, de Korte D, Ramirez-Arcos S, Savelkoul PH, Pettersson A: Distribution, origin and risk of coagulase-negative staphylococci from platelet concentrates. J Med Microbiol 2011;60:592-599.

- 36 Baer VL, Lambert DK, Henry E, Snow GL, Sola-Visner MC, Christensen RD: Do platelet transfusions in the NICU adversely affect survival? Analysis of 1,600 thrombocytopenic neonates in a multihospital healthcare system. J Perinatol 2007;27:790-796.

- 37 Garcia MG, Duenas E, Sola MC, Hutson AD, Theriaque D, Christensen RD: Epidemiologic and outcome studies of patients who received platelet transfusions in the neonatal intensive care unit. J Perinatol 2001;21:415420.

38 Del Vecchio A, Sola MC, Theriaque DW, Hutson AD, Kao KJ, Wright D, Garcia MG, Pollock BH, Christensen RD: Platelet transfusions in the neonatal intensive care unit: factors predicting which patients will require multiple transfusions. Transfusion 2001:41:803-808.

- 39 Josephson CD, Su LL, Christensen RD, Hillyer $\mathrm{CD}$, Castillejo MI, Emory MR, Lin Y, Hume H, Easley K, Poterjoy B, Sola-Visner $\mathrm{M}$ : Platelet transfusion practices among neonatologists in the United States and Canada: results of a survey. Pediatrics 2009;123:278285.

-40 Del Vecchio A, Latini G, Henry E, Christensen RD: Template bleeding times of 240 neonates born at 24 to 41 weeks gestation. J Perinatol 2008;28:427-431.

-41 Sallmon H, Gutti RK, Ferrer-Marin F, Liu ZJ, Sola-Visner MC: Increasing platelets without transfusion: is it time to introduce novel thrombopoietic agents in neonatal care? J Perinatol 2010;30:765-769.

-42 Blajchman MA, Glynn SA, Josephson CD, Kleinman SH, State-of-the-Science Symposium Transfusion Medicine Committee: Clinical trial opportunities in transfusion medicine: proceedings of a National Heart, Lung, and Blood Institute State-of-the-Science Symposium. Transfus Med Rev 2010; 24:259-285. 